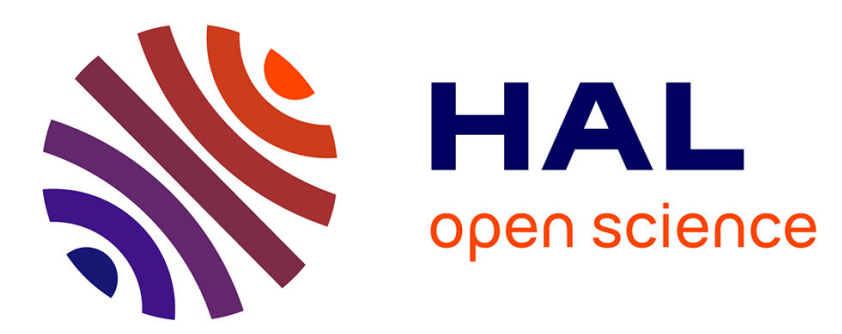

\title{
Flexibility of wages and macroeconomic instability in an agent-based computational model with endogenous money \\ Pascal Seppecher
}

\section{- To cite this version:}

Pascal Seppecher. Flexibility of wages and macroeconomic instability in an agent-based computational model with endogenous money. Workshop on Economic Heterogeneous Interacting Agents ESHIA/WEHIA 2010, Jun 2010, Alessandria, Italy. hal-00661956v2

\section{HAL Id: hal-00661956 \\ https://hal.univ-cotedazur.fr/hal-00661956v2}

Submitted on 7 Jun 2017

HAL is a multi-disciplinary open access archive for the deposit and dissemination of scientific research documents, whether they are published or not. The documents may come from teaching and research institutions in France or abroad, or from public or private research centers.
L'archive ouverte pluridisciplinaire HAL, est destinée au dépôt et à la diffusion de documents scientifiques de niveau recherche, publiés ou non, émanant des établissements d'enseignement et de recherche français ou étrangers, des laboratoires publics ou privés. 
This article has been published in a revised form in Macroeconomic Dynamics http://dx.doi.org/10.1017/S1365100511000447]. This version is free to view and download for private research and study only. Not for re-distribution, re-sale or use in derivative works. 


\title{
Flexibility of wages
}

\section{and macroeconomic instability \\ in an agent-based computational model \\ with endogenous money}

\author{
Pascal Seppecher*
}

2012

\footnotetext{
*University of Nice Sophia-Antipolis, Center for Studies in Macroeconomics and International Finance, (France). Email: p.seppecher@free.fr. The model presented is implemented as a Java application (Jamel: Java Agent-based MacroEconomic Laboratory). This application, together with the scenarios presented in this paper, is executable on the webpage http://p.seppecher.free.fr/jamel/. On this page, the interested reader can find the source code of the last version of the model and a technical appendix.
} 


\begin{abstract}
We present a model of a dynamic and complex economy in which the creation and the destruction of money result from interactions between multiple and heterogeneous agents. In the baseline scenario, we observe the stabilization of the income distribution between wages and profits. We then alter the model by increasing the flexibility of wages. This change leads to the formation of a deflationary spiral. Aggregate activity decreases and unemployment increases. The macroeconomic stability of the model is affected and eventually a systemic crisis arises. Finally, we show that the introduction of a minimum wage would have allowed to boost the aggregate demand and to avoid this crisis.
\end{abstract}

Keywords: monetary economics, labor market dynamics, agents based modeling 


\section{Introduction}

In the General Theory, Keynes insists on the necessity of taking into account "the complexities and interdependencies of the real world" (Keynes 1974). He strongly criticizes the methods which "expressly assume strict independence between the factors involved". For Keynes, it is "the nature of economic thinking" to "allow, as well as we can, for the probable interactions of the factors amongst themselves."

Among the complex problems approached by Keynes in the General Theory, we find the question of the effects of a decrease in nominal wages on the level of unemployment, prices, and the equilibrium of the whole system. Keynes criticizes the view according to which unemployment would find its explanation in the existence of "frictional resistances" preventing wages to adapt to the aggregate demand of labor. For him, one cannot argue by supposing fixed the aggregate effective demand:

(...) the precise question at issue is whether the reduction in money-wages will or will not be accompanied by the same aggregate effective demand as before measured in money, or, at any rate, by an aggregate effective demand which is not reduced in full proportion to the reduction in money-wages $(. .$.$) (Keynes$ 1974)

According to Keynes, the effects of a fall in nominal wages are not limited to the labor market. Because the level of effective demand can be modified, 
these effects can extend to the prices of goods, and affect the stability of the whole economy.

For if competition between unemployed workers always led to a very great reduction of the money-wage, there would be a violent instability in the price-level. Moreover, there might be no position of stable equilibrium except in conditions consistent with full employment (Keynes1974)

Keynes paints the picture of the economy as a system in which the interactions between elements (households and firms) are real and monetary simultaneously. Because in this system the interdependences are multiple, we cannot study the effects of the variation of one of its elements without examining the effects on other elements and the possibility of positive or negative feedback. The representation of the economy that Keynes gives us corresponds to what we call today a complex system.

A complex system is a system composed of units interacting according to simple rules, but which exhibits emergent properties, that is, macroscopic properties arising from the interactions of the units that are not properties of the individual units themselves (Simon 1962). If we consider economic systems as complex systems, then agent-based modeling constitutes an essential tool to investigate their properties and study their dynamics (Arthur 2006, Leijonhufvud 2006, Howitt 2008).

This paper presents a computational macroeconomic model which closely 
associates Keynesian thinking and an agent-based approach.

In section 2, we describe the construction of the model. In this model, real and monetary quantities are strictly distinguished. Money is endogenous: its flow and its reflux are determined by the interactions between the agents composing the system. In section 3, we describe the implementation of the model. We show how the use of object-oriented programming language allow to simulate real and monetary constraints.

In section 4 , we study the behavior of the model. We observe the emergence of macroeconomic regularities characterized by the stability of the distribution of total income between wages and profits. In section 5 , we alter the model by increasing the flexibility of wages. We then observe a fall in aggregate demand. Firms react by cutting prices and production. The development of the deflationary spiral leads to a systemic crisis. Finally, we show that the introduction of a minimum wage boosts demand and avoids the failure of the system.

\section{Model}

The model presented follows the principles of the agent-based computational approach (Tesfatsion 2006, Farmer and Foley 2009). It is a decentralized model, populated with multiple, heterogeneous, autonomous and rival agents who interact in the real and monetary levels simultaneously. The macroscopic

properties of the model are not postulated, they are emergent properties of 
the complex system formed by the interactions between the agents.

\subsection{General characteristics}

The model is formed by two coupled systems: the first representing the real sphere, the second the monetary sphere. The rules of functioning of these two systems are imposed upon the agents. Figure 1 gives a representation of the real and monetary interactions projected on two parallel plans.

\section{[Figure 1]}

The model contains three types of agents: firms (one hundred), households (one thousand) and a banking sector (one single representative bank). It respects the post-Keynesian principle of endogenous money (Moore 1979, Lavoie 1984): In the model, all money is created by bank credit for production financing ${ }^{1}$.

\footnotetext{
${ }^{1}$ The possibility of a convergence between Keynesian thinking and agent-based modeling has been shown by (Bruun 1999). In this early paper, she emphasized the importance of the monetary consistency for such models. More recently, Cincotti, Raberto and Teglio (2010) presented an agent-based model in which money depends on the supply of credit from a complex banking sector. In our contribution the banking system is much simpler. However our model fully respects the endogenous money principle. It is a simple stock-flow consistent agent-based model that focuses on the dynamics of wages, prices and profits.
} 


\subsection{Bank}

In its role of payment agent, the bank has no autonomy. It merely executes the payment orders of the account-holders, as long as the outstanding balance is positive. In its role in production financing, the bank is accommodating: it satisfies the demand for credit by firms. When a firm is unable to pay off a loan in due terms, the bank automatically grants a new one that is termed doubtful. The amount thereof is enough to allow the firm to pay off the initial loan at once. On the other hand, when a firm is unable to pay off a doubtful debt when due, the firm goes bankrupt and disappears. The bank then has to absorb the defaulted debt.

For that purpose, the bank has a reserve (the bank equity) from which it draws to absorb the debt of the failing firm. The bank then uses its resources

(interest-payments made by firms) in order to recapitalize up to the required level. The surplus of its resources is paid to its shareholders under the form of dividends. However, sometimes, the bank equity may be insufficient to cover the bankruptcy of a debtor. The unique bank goes bankrupt and the simulation breaks off.

\section{$2.3 \quad$ Firms}

At the beginning of each period, every firm determines its production target. Firms do not observe exactly the condition of the goods market but rather estimate it based on the level of their own stock of unsold goods. When the 
latter are large, a firm lowers its levels of production and employment.

The firm then updates the wage offered on the labor market. Here too, the reaction of the firm depends on its own assessment of the labor market situation. If during several consecutive periods the firm has experienced difficulties in recruiting employees, then it increases its starting wage.

The firm can then calculate its payroll and determine its external financing need. The desired loan is automatically provided by the bank. The firm posts its offer on the labor market. The households which respond are paid and employed by the firm.

Once the phase of production is finished, the firm determines its price. The new price depends on inventories levels. If the firm thinks that the level of inventories is too high, it lowers the price, otherwise it increases the price. The firm then posts its offer on the goods market and satisfies the demand of the households at that price.

The firm now must pay off the due debts. As we have already explained, if the firm has not enough money to pay off its doubtful debts, it immediately goes bankrupt and disappears. Its debt is cancelled, absorbed by the bank.

Each period, the profits of the firm are formed by its revenues from sales minus the costs of production (wages and interests on loans). When profits are positive, the firm distributes a fraction to households through dividends and keeps the rest to build up internal-financing for future production. 


\subsection{Households}

Like firms, households have only a limited knowledge of the labor market. Every unemployed household makes a search: it consults the vacancies of a limited number of employers chosen at random among all the offers posted on the labor market. The household considers the highest wage offer among the consulted vacancies. If the wage offer is higher than its reservation wage, the household accepts the job and it is hired at once by the firm. Otherwise, it remains unemployed in this period. The level of the reservation wage depends on the number of periods spent in a state of unemployment. After a certain time, the unemployed household accepts to lower its reservation wage.

Once the labor market closes down, the firms pay the employed households. In exchange, these expend their labor power in the implementation of the process of production. The household income is the sum of the wage of the period and the possible dividends paid by firms and the bank. The households save a part of their income, and spend the other on the goods market. As on the labor market, the households have only a limited knowledge of the goods market: each consults only a limited number of bids, and chooses the most interesting among them.

\section{Implementation}

In their pioneering work, Cyert and March (1963) show that computer programming provides the "natural theoretical language" for modeling complex 
dynamic social systems. It is even more true since the later development of object-oriented languages. By nature, object-oriented programming is modular and thus particularly adapted to model decentralised systems in which many heterogenous agents act in parallel. For Tesfatsion (2006), "every graduate economics program should incorporate general programming language requirements".

In computer science, an object is an integrated unit of data (properties) and procedures (methods) that can act on these data. Data and procedures implementation is encapsulated within the object: the internal structure of the object is hidden from other objects, only the object's own methods can directly manipulate its properties. In our model, the encapsulation of the real and monetary data within objects ensures compliance with physical constraints - rules of production, transfer and destruction of the goods and with monetary constraints - rules of creation, transfer and destruction of the money.

Let us consider one of the simplest objects within the model: the object named Deposit which represents a money deposit at the bank. This object has a single property — a positive integer which stands for the deposit amount - and three self-explanatory methods - debit(), credit(), getAmount ().

Another example is the Bank object. Each Deposit object is a property of the Bank object. Thus, the agents cannot manipulate directly the money deposits. When an agent has to make a payment, he gives a Cheque object 
to the payee-agent. The latter hands the Cheque object to the bank. The bank verifies that sufficient funds exist in the drawer account to cover the cheque. If true, an internal (private) method named transfer() calls the debit() method of the drawer account and the credit() method of the payee account. Then the Cheque object is cancelled.

The Bank object is also composed of a collection of Loan objects which represents debts. A Loan object encapsulates a set of properties such as the loan amount, the interest rate, the due date, the loan quality. When the bank lends to an agent, a new Loan object is created for the loan amount and this amount is immediately credited to the borrower deposit. At the end of each period, the bank goes through its collection of loans searching for due loans. For each due loan, the due amount is debited from the borrower deposit and the Loan object is cancelled. So all bank procedures - such as transfer(), lend (), debtRecovery() - guarantee the fundamental accounting equation:

$$
\underbrace{\text { Bank assets }}_{\text {Loans }}=\underbrace{\text { Bank liabilities }}_{\text {Deposits }}+\underbrace{\text { Bank capital }}_{\text {Retained earnings }}
$$

Once the objects and internal procedures of the monetary sphere are developed and tested, their complexity can be forgotten. All these procedures are hidden from others agents, which have only access to some public methods which allow them to consult the available amount on their own account, to deposit a cheque and to ask for a loan. Nonetheless, this complexity of the monetary sphere is fundamental: as in the real world, it is an essential feature to guarantee that all the money which circulates in the model comes from 
somewhere and goes somewhere. There is no "black hole" (Godley and Lavoie 2007).

Thanks to object-oriented programming, this stock-flow consistency principle can be extended to the real sphere modeling. In our model each Household agent is endowed with a LaborPower object. A LaborPower object can take two values: available and exhausted. At the beginning of each period, all LaborPower objects are available. When a household works, its LaborPower changes to exhausted. Thus, a household can expends its labor power only once in a period.

In order to work, a Household agent must be in relation with a Machine object. A Machine object encapsulates two properties: the first, constant, which represents its productivity, the second, variable, which represents the progress of the production process. Each time a household expends its labor power on a machine, the progress of this machine production process is incremented. When the process of production is achieved, the machine delivers a volume of commodities proportional to its productivity.

We see that the data encapsulation within objects guarantees that all commodities present in the model have been created by the expenditure of a household labor power on a machine. Requiring several successive expenditures of labor power, the internal production process of a machine spreads over several periods. In fact, this detail of the Machine object implementation is an essential characteristic of the model which relates real and monetary spheres, since it is because production takes time that firms need bank credit 
to finance production process (Godley and Lavoie 2007).

Once the real and monetary objects are designed, we have to construct the agents who will manipulate them. An agent - household or firm - is nothing else but a complex object endowed with behavior methods which allow the agent to react and even to adapt to his environment. In a complex dynamic model uncertainty is endogenous (Delli Gatti, Gaffeo and Gallegati 2010): rational expectations are impossible, and agents cannot maximize. In order to model agents behavior, we call up the notion of "procedural rationality" (Simon 1996): agents use rules of thumb or heuristics to adjust their behavior. The principle of parsimony leads us to design these methods: they are simple adjustment procedures around exogenous normal values. Among these values there is the inventory normal level (from 1 to 4 months of production) used by firms to adjust production level and price level, or the saving normal level (5\% of the annual income) used by households to adjust their consumption level. In the following sections, we focus on the role played in the model by one of these exogenous parameters - the resistance of the unemployed households to a decrease of nominal wages — in the emergence of a macroeconomic stability. 


\section{Emergence of a macroeconomic stability}

\subsection{Stability of income distribution}

We conduct a large number of simulations by varying the main parameters of the model one after the other. We find that the model is able to reproduce itself from one period to another, in a wide space of parameters, with strong regularities of behavior. Then we test these regularities by simulating an exogenous shock at a given date with a sudden variation of one of the parameters of the model.

In the baseline model, the productivity level is constant. We increase the productivity of all units of capital simultaneously in order to simulate a dramatic technological innovation. In the short run, the raise in productivity increases the profitability of the firms. But the production exceeds the consumption, and the inventory levels increase. So firms cut down the production. The unemployment rises and prices drop. We observe an increase of doubtful debts and bankruptcies. In the long run the system weathers the storm. Profits, which have jumped in keeping with the increase in productivity, gradually return to their previous levels. Income distribution is not affected over the long term (figure 2a).

In another scenario, we double the households saving propensity so as to simulate the impact of a negative expenditure shock. Again, the shock entails a deep destabilization of the model in the short term. As in the current version of the model there is no investment, all savings remain unused in 
monetary form. So, the increase of savings leads to a slow down in money circulation. The weakening of demand affects the cash flow of the firms. Many firms have difficulties in paying off their debts, and the capital of the bank is affected by the bankruptcies of some of them. In the long run, income-distribution stabilises again, this time with a lower level for the share of the profits. We can show that a new inverse shock, reversing the households saving propensity to its previous level, helps restore the previous distribution levels (figure 2b).

[Figure 2]

Beyond these two examples, all the simulations we conducted show that there is a wide range of values in the space of the parameters of the model for which we observe a long-term stability of income-distribution. The macroeconomic equilibrium of the model seems strongly connected to this stability.

Nothing in the behavior assigned to firms foreshadowed the stability of income-distribution between wages and profits. We established that firms set prices and wages in a strictly independent way. In particular, every firm ignores its costs and can easily sell its production below its production cost (the latter being essentially formed by the payment of wages). Nevertheless, we observe that the average price on the goods market settles above the production cost at a level stabilising the average margin of firms and thus the share of the profits in the total income.

The long-term stability of the income distribution between wages and 
profits, the main appearance of the macroeconomic equilibrium of the model, is thus an emergent property of the model, testifying to the existence of a macroscopic coordination between the price formation on the goods market and the wages formation on the labor market.

This emergent property of the model illustrates the observation of Keynes, according to whom the stability of the income distribution constitutes a "wellknown statistical phenomenon":

The stability of the proportion of the national dividend accruing to labor $(\ldots)$ is one of the most surprising, yet best-established, facts in the whole range of economic statistics, both for Great Britain and for the United States. (...) the result remains a bit of a miracle. (Keynes 1939)

\subsection{Rigidity of wages}

In the baseline scenario, the resistance of the unemployed households to a decrease of wages is fixed to 8 months on average (between 4 and 12 months). For these first months of unemployment, the reservation wage of each household is equal to the last wage earned by the household when it was employed. After this lapse, the household which did not find a job lowers its reservation wage by 10 percent.

[Figure 3] 
However, after the first five years of the simulation, the average duration of unemployment becomes established at approximately two and a half months. Most of the unemployed households thus find a job before lowering their reservation wage. In these circumstances, wages seem very sticky downward. This rigidity appears as responsible for the simultaneous presence of vacancies and unemployed households. The shape of the Beveridge's curve shows that the number of vacancies and the number of unemployed households varies in the same direction (figures 3a to 3c).

The households staying without a job in the baseline scenario appear to be responsible for their condition, because we notice vacant jobs simultaneously. The unemployment so observed is usually considered as 'voluntary unemployment'.

\section{Experiments on the labor market}

In Seppecher (2010), we showed the essential role played by the banking system in the emergence of the macroeconomic stability of the model. Here, we ask ourselves if the rigidity of the labor market plays a role in this emer-

gence. In a first experiment, we test the stability of the model by increasing the flexibility of the nominal wages. In a second experiment, on the contrary we strengthen the downward rigidity in nominal wages by introducing a minimum wage. 


\subsection{Flexibility of wages}

We modify the reference scenario by reducing, from 2030, the resistance of the households to a drop of wages. From this date the households agree to lower their reservation wage after 3 months of unemployment on average (between 2 and 4 months).

[Figure 4]

At first sight, results on the labor market are in accordance with the expected effects. The unemployed households lower their reservation wage more quickly. The average duration of unemployment is reduced. The curves of the number of vacancies and the unemployment figures are disconnected. The shape of the Beveridge's curves observed here and in the baseline scenario are very different (figures $4 \mathrm{a}$ to $4 \mathrm{c}$ ).

$$
\text { [figure 5] }
$$

However, the weakening of wages affects aggregate demand. Consumption drops below the production level, leading to an increase in inventories. Firms react by lowering their prices but also by reducing the level of the production, thereby generating an increase in unemployment (figures $5 \mathrm{a}$ to $5 \mathrm{~d}$ ).

This feedback on the labor market, by increasing the number of unemployed households, increases the competition between them, and leads them to accept incessantly new reduction in wages. The deflation process, set off by the first decreases in wages, grows and strengthens itself. 
The course of the Phillips curve illustrates the sinking of the economy into the depression. The fall of nominal wages, faster than the drop of prices, leads to a decline in real wages. Income distribution is destabilised in favor of the share of the profits. Firms have more and more difficulty in paying off the bank when loans are due. Bad debts increase, bankruptcies grow, affecting the capital of the bank, until leading this one to failure (figures $5 \mathrm{e}$ to $5 \mathrm{~h}$.

Because the model is endowed with a unique bank representative of the whole banking system, the bankruptcy of this bank translates into an impossibility to respect the reflux constraint, imposed by the credit nature of money. The crisis is systemic and the simulation breaks down.

\subsection{Institution of a minimum wage}

We modify again the scenario. We keep the modification of the flexibility of wages in 2030 but we introduce in 2045 a minimum wage (figures $6 \mathrm{a}$ to $6 \mathrm{~h}$ ).

The institution of the minimum wage interrupts the fall of wages. However, as at first the prices pursue their decline, the employed households see their real wages increasing. Consumption exceeds production and firms inventories decrease. This demand recovery leads firms to interrupt the fall in prices and to increase production.

Unemployment decreases and the wage bill increases, feeding again aggregate demand. The economy goes up again along the Phillips curve and stabilises at levels of activity higher than those observed in the reference scenario. The distribution of income between wages and profits returns to levels 
close to those of the baseline scenario.

[Figure 6]

\section{Conclusion}

The agent-based computational methods enable the modeling of complex systems populated with a large number of autonomous and heterogeneous agents. Using this approach, we built a computational model of a dynamic and complex economy in which the interactions between the agents are real and monetary.

We notice the emergence of a macroeconomic stability - characterized by long-term stability of the distribution of the total income between wages and profits. In its basic version, this model contains a very rigid labor market. The unemployed households strongly resist against the fall in the nominal wages that firms try to impose. This resistance generates the simultaneous persistency of a significant number of unemployed households and vacancies.

We then modified the resistance to downward nominal wage flexibility by forcing unemployed households to accept lower wages more easily. While households are more flexible to the demands of employers, we observed no sustained reduction in level of unemployment. In contrast, downward wage adjustments lead to a weakening demand. This weakening of demand led firms to lower commodity prices but also the level of production, with conse-

quent increases in unemployment. It sets up a self-feeding process of deflation 
that eventually leads to the bankruptcy of the banking system. This scenario illustrates and confirms the reasoning of Keynes, which leads him to assert that a fall in the nominal wages cannot garantee the achievement of full employment, and could even destabilize prices and the whole economic system.

The following scenario, with institution of a minimum wage, confirms the importance of wage rigidity for the emergence of the macroeconomic stability noticed in the baseline scenario. According to Keynes, it is the monetary character of the considered economy that explains the importance of this rigidity for the equilibrium of the system:

In fact we must have some factor, the value of which in terms of money is, if not fixed, at least sticky, to give us any stability of values in a monetary system. (Keynes1974)

The model which we used remains very simple with respect to the requirements expressed by Keynes in the General Theory. Nevertheless, no theoretical obstacle seems to rule out extensions to the elements of the real world which have been disregarded in this first version.

\section{Acknowledgment}

Sincere thanks to Nicolas Groshenny, Marc Lavoie, Alexandru Minea, Johanna Niaba, Marc Pilkington, Tom Pilkington and two anonymous referees for their helpful corrections and comments. 


\section{References}

- Arthur, W. Brian (2006) Out-of equilibrium economics and agent-based modeling. In Leigh Tesfatsion and Kenneth L. Judd (ed.), Handbook of Computational Economics, vol. 2, pp. 1625-1637. Amsterdam: Elsevier/North-Holland.

- Bruun, Charlotte (1999) Agent-Based Keynesian Economics - Simulating a Monetary Production System Bottom-Up. Aalborg University.

- Cincotti, Silvano, Marco Raberto, and Andrea Teglio (2010) Credit Money and Macroeconomic Instability in the Agent-based Model and Simulator Eurace. Economics: The Open-Access, Open-Assessment EJournal, 4(26).

- Cyert, Richard M., and James G. March (1963) A Behavioral Theory of The Firm. Englewood Cliffs, New Jersey: Prentice-Hall.

- Delli Gatti, Domenico, Edoardo Gaffeo, and Mauro Gallegati (2010) Complex agent-based macroeconomics: a manifesto for a new paradigm. Journal of Economic Interaction and Coordination, 5(1), 5.

- Farmer, J. Doyne, and Duncan Foley (2009) The economy needs agentbased modelling. Nature, 460(August 6), 685-686.

- Godley, Wynne, and Marc Lavoie (2007) Monetary economics, An Integrated Approach to Credit, Money, Income, Production and Wealth. 
Basingstoke: Palgrave Macmillan.

- Howitt, Peter (2008) Macroeconomics with intelligent autonomous agents. In Roger E. A. Farmer (ed.), Macroeconomics in the small and the large: essays on microfoundations, macroeconomic applications and economic history in honor of Axel Leijonhufvud. Cheltenham (UK), Northampton (USA): Edward Elgar.

- Keynes, John Maynard (1939) Relative movements of real wages and output. The Economic Journal, 49(193).

- Keynes, John Maynard (1974) The General Theory of Employment, Interest and Money. New York: Macmillan, St. Martin's Press and London: Cambridge University Press.

- Lavoie, Marc (1984) The endogenous flow of credit and the post keynesian theory of money. Journal of Economic Issues, 18(3), 771-797.

- Leijonhufvud, Axel (2006) Agent-based macro. In Leigh Tesfatsion and Kenneth L. Judd (ed.), Handbook of Computational Economics, vol. 2, pp. 1625-1637. Amsterdam: Elsevier/North-Holland.

- Moore, Basil. J. (1979) The endogenous money stock. Journal of Post Keynesian Economics, 2(1), 49-70.

- Seppecher, Pascal (2010) Dysfonctionnement bancaire, bulle du crédit et instabilité macroéconomique dans une économie monétaire dynamique 
et complexe. Revue Economique, 61(3).

- Simon, Herbert Alexander (1962) The architecture of complexity, Proceedings of the American Philosophical Society, 106(6).

- Simon, Herbert Alexander (1996) The Science of artificial. Cambridge (MA): MIT press.

- Tesfatsion, Leigh. (2006) Agent-based computational economics: a constructive approach to economic theory. In Leigh Tesfatsion and Kenneth L. Judd (ed.), Handbook of Computational Economics, vol. 2, pp. 1625-1637. Amsterdam: Elsevier/North-Holland. 


\section{$\begin{array}{ll}7 & \text { Figures }\end{array}$}

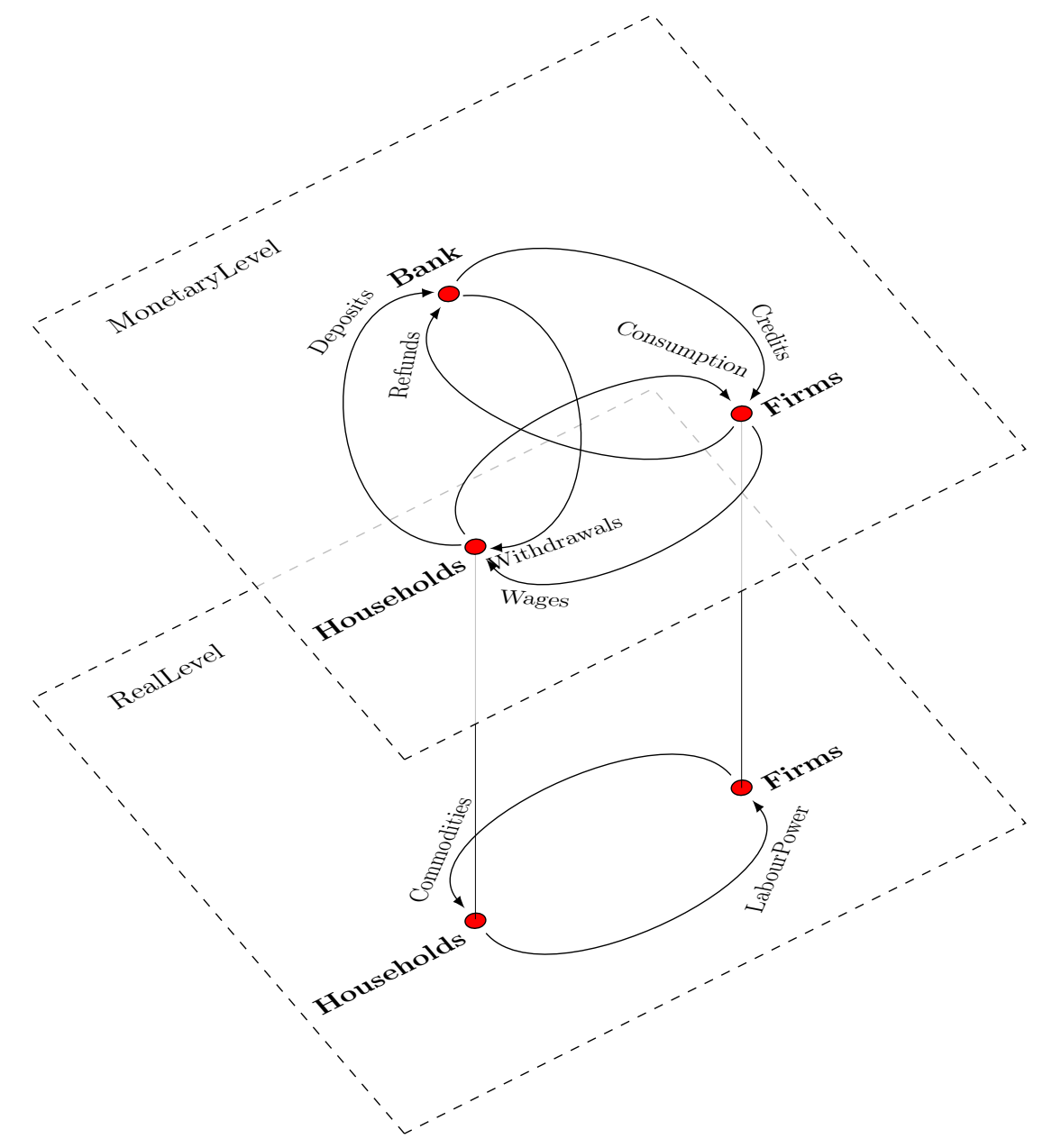

Figure 1: The real and monetary interactions between the agents 


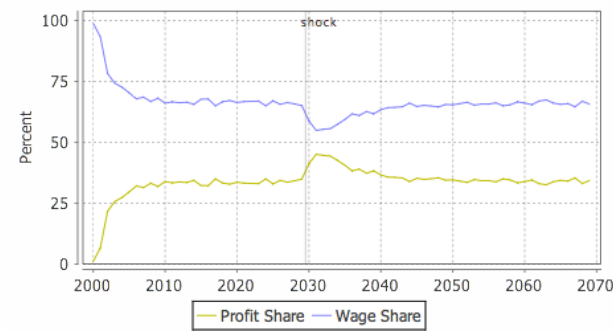

(a) Productivity shock

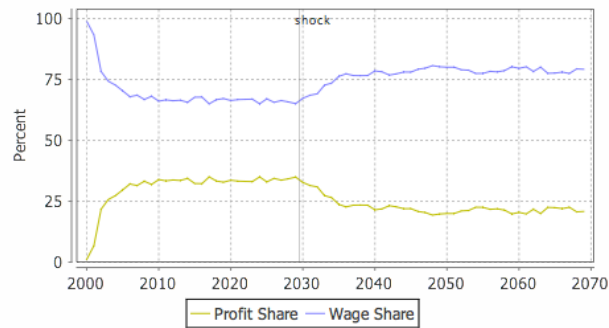

(b) Negative expenditure shock

Figure 2: Effects of exogenous shocks on the income distribution

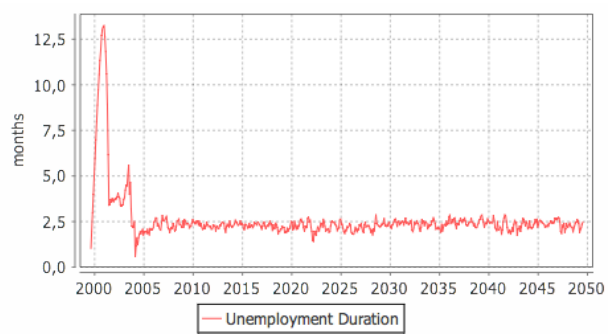

(a)

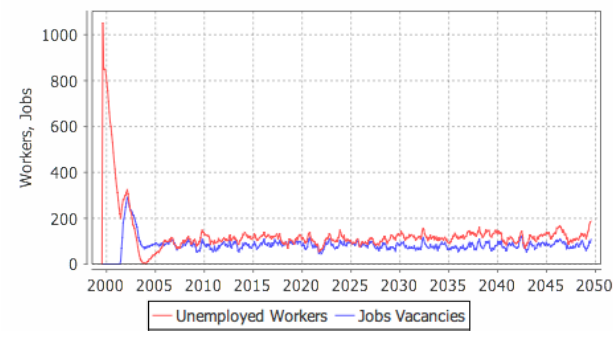

(b)

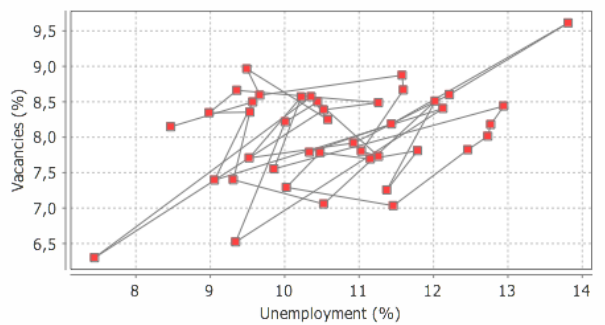

(c)

Figure 3: Rigidity of wages in the baseline scenario 


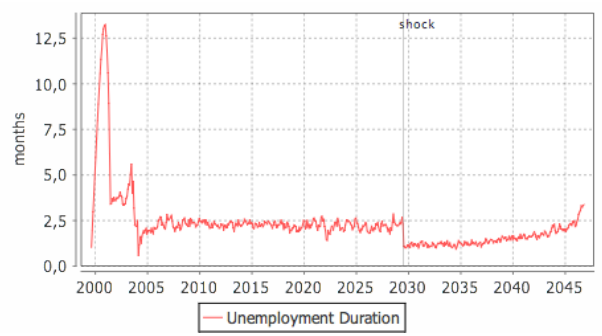

(a)

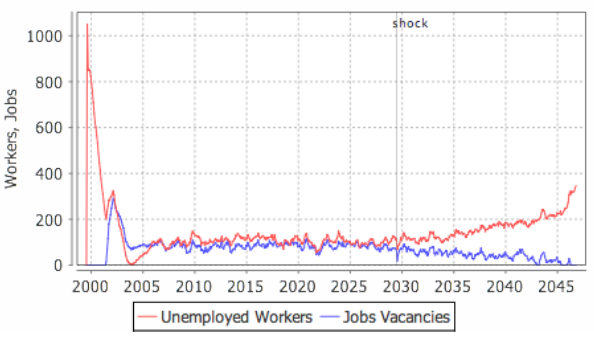

(b)

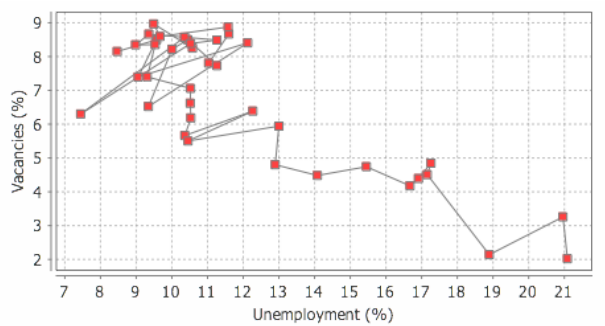

(c)

Figure 4: Flexibility of wages: effects on the labor market 


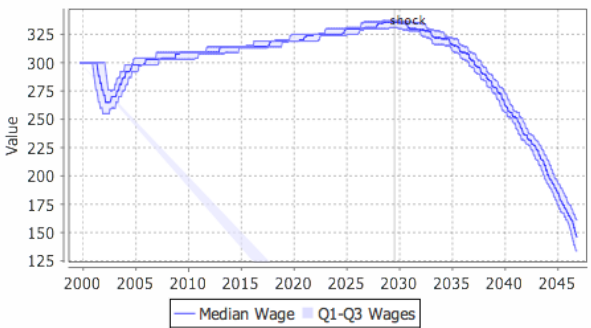

(a)

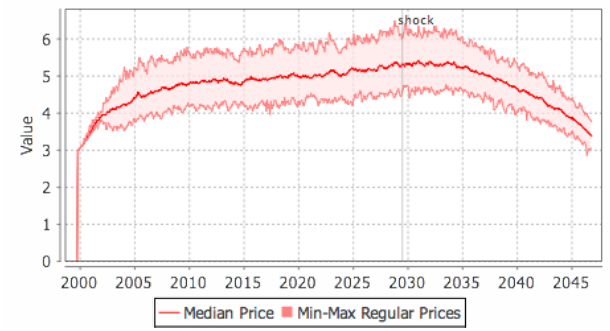

(c)

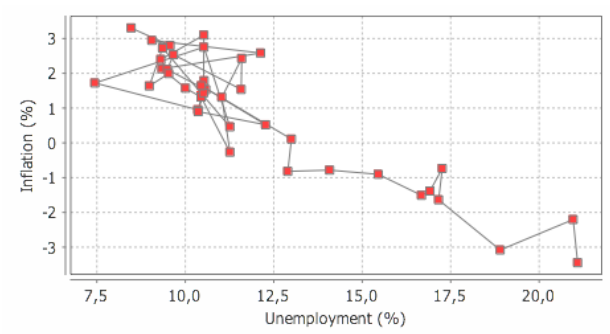

(e)

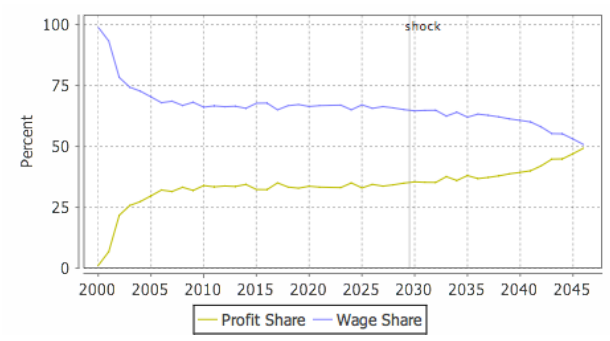

(g)

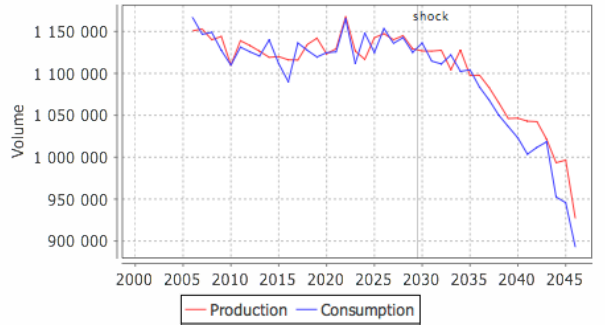

(b)

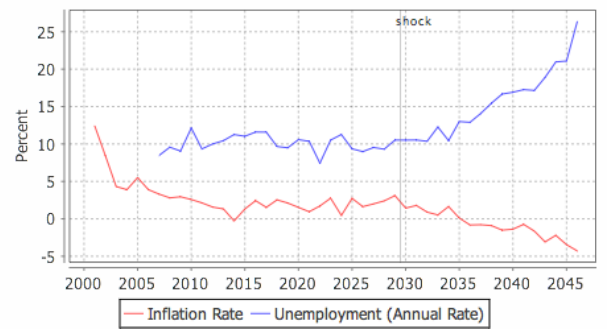

(d)

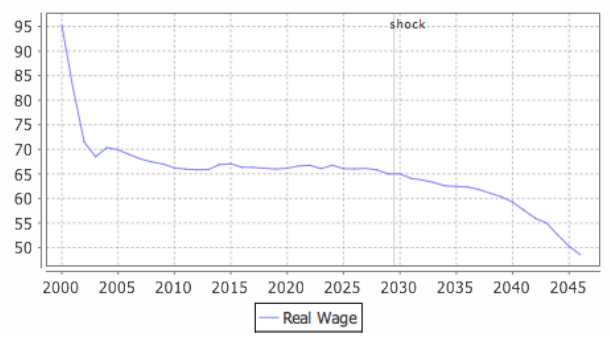

(f)

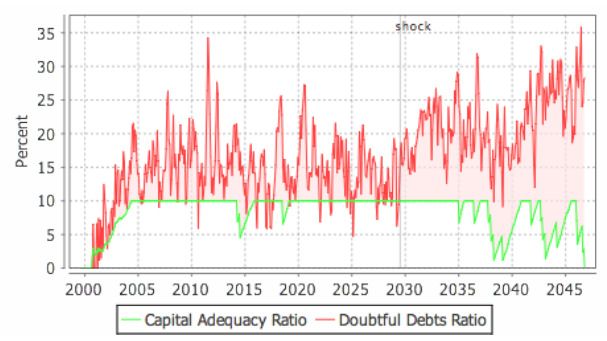

(h)

Figure 5: Wages flexibility: effects on demand and activity 


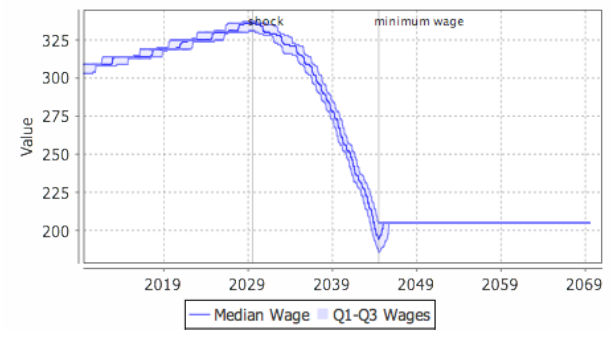

(a)

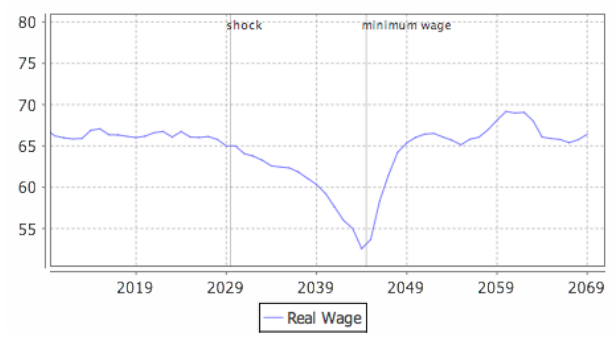

(c)

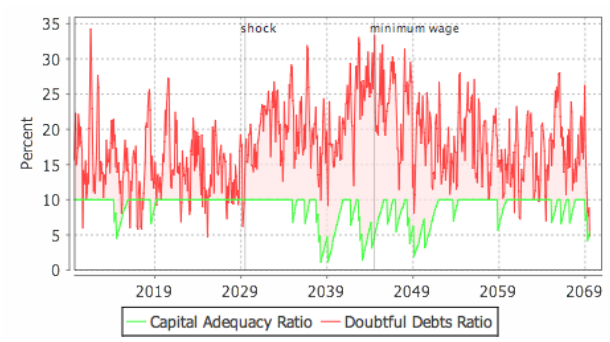

(e)

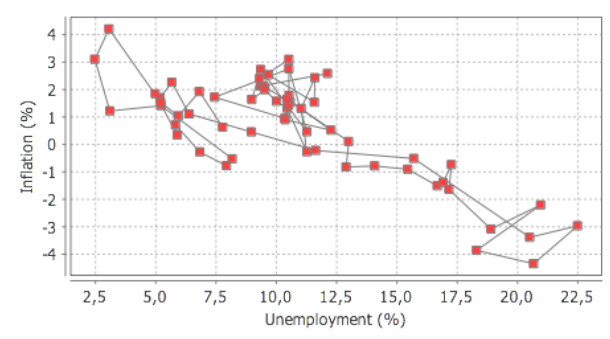

(g)

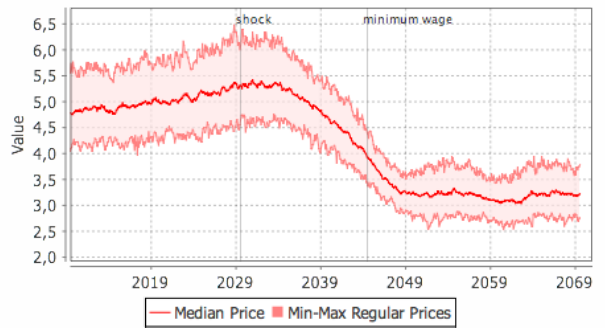

(b)

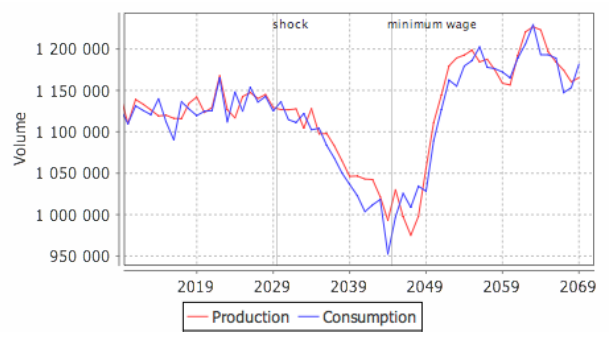

(d)

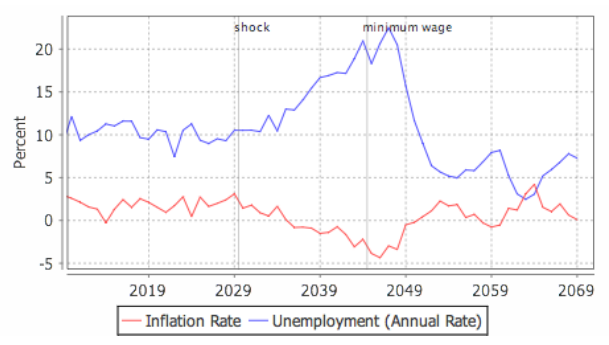

(f)

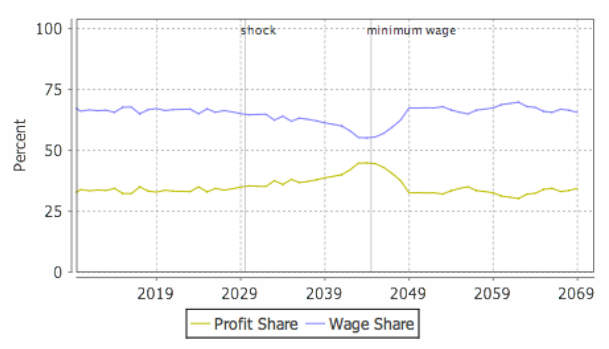

(h)

Figure 6: Institution of a minimum wage 